\title{
Effect of Internship Program on Self-Reported Clinical Competence among BSc Nursing Students in Selected Nursing Colleges at Mangaluru
}

\author{
Sujatha R. Kannappan ${ }^{1, \odot ~ V i n e e t h a ~ S u n n y ~}{ }^{1}$
}

Address for correspondence Sujatha R. Kannappan, MSc, Department of Child Health Nursing, Nitte Usha Institute of Nursing Sciences, Nitte (Deemed to be University), Deralakatte, Mangalore 575018, Karnataka, India (e-mail: sujathakannappan@gmail.com).

J Health Allied Sci Nu 2020;10:9-14

\section{Introduction}

Nursing is one of the professions which is noble by its character, which indeed serves humanity, alleviates suffering, and facilitates healing. It is the profession within the health care sector focused on the care of individuals, families, and communities, so they may attain, maintain, or recover optimal health and quality of life. Trained nursing personnel are the backbone of the health care team, who made contact with the human from birth to death. Advanced practice nurses who are capable of transforming theoretical knowledge into practice to provide maximum patient care, which is needed more now than ever. Nursing is at crossroads with unlimited opportunities in hospitals, communities, and research and health development programs. In this context, the importance of a clinically competent nurse is inevitable. A clinically competent nurse should be able to perform a specialized task related to patient care at any time without difficulties. 
A nurse who excels in his/her profession should be an allaround person with many good qualities. They should be able to be compassionate, caring, intelligent, good at the problem solving individual, and must act meticulously in critical situations. ${ }^{1}$ No one is competent by birth; it will be only gained through practice. A nursing student should be trained during the study period to be a clinically competent nurse. The internship program designed by nursing colleges is building a platform to create a seemliness transition from a nurse student to clinically competent nursing professionals.

\section{Background of Study}

In the early period, nurse competence tested through observation in clinical settings complemented with a practical and written examination. Nursing preparation involved acquiring theoretical knowledge and implementation of it in the care of patients. It includes the assessment of the personal qualities of a nurse such as values, skills, judgment, and attitude. ${ }^{2}$

This system was designed to ensure that in addition to merely passing an exam, nurses acquired competence and possessed adequate personal attributes.

Nursing training is a blend of knowledge performance, skill, value, and attitudes. Nursing competency is an indefinable assemble which cannot be observed directly. Competency standards are how effectively nurses act in the nursing team, which is often reflected by characteristics of competency possessed by them. Aging and population growth increase the demand for skilled nurses. In the modern world, supplying experienced and qualified caregivers are the challenges faced by hospitals. Nursing educators have a crucially important role in developing the nursing workforce, especially under-tightening constraints, and the cost of training new nurses remains significant. Adjusting to new roles and consolidating the knowledge and skills can be stressful to the nurses who are in the transition period from student to newly qualified nurses. During this period, many newly qualified nurses reported the feeling of inadequately prepared. Difficulty during the transition period reduced by various strategies, which aim to increase confidence, competence, sense of belonging, improve recruitment, retention, and reduce turn over costs of new graduates. ${ }^{3}$

The major component of the clinical nursing practice is to manage and coordinate the work in the complexity of clinical context. Clinical nursing practice is a composite skill, quickly internalized, constantly unrecognized and undervalued. A clinical pathway developed to provide the structure and preceptor support for the learning experience, which means explicating and conceptualizing the staff nurse role and provides an overview of components that suggest a time and action framework that has to progressively develop in goal-directed activities. Student clinical practice is an essential and significant part of nursing education, and the clinical placements should be positive and valuable. The clinical placements must ensure an environment that is conducive to learning, and promotes the personal and professional development of nursing students. ${ }^{4}$ According to Cheng et al, at the time of graduation, students in all three nursing programs perceived low competence in overall clinical skills. Students in a 2-year RN-BSN night school perceived a significantly lower competence than students to other types of nursing programs. The results of the study insisted on reinforcement before graduation on nursing student's general performance skills and advanced nursing skills. ${ }^{5}$

The aim of the study is to assess the effect of internship on the level of clinical competence of BSc nursing students in selected nursing colleges at Mangaluru measured by using clinical competence questionnaire (CCQ).

In this study, clinical competencies refer to development of knowledge, skills of students following their practice during internship period in the clinical settings related to patient care which will be assessed by CCQ includes four competence components: (1) the nursing professional behaviors, (2) the general performance, (3) the core nursing skills, and (4) the advanced nursing skills.

Internship program: A period of apprenticeship for a nursing college graduate who serves in a hospital for a specified period before beginning professional practice.

\section{Methodology}

Quantitative research approach and pre-experimental design were used for this study. The purposive sampling method was used to select nursing colleges because these students were exposed to different private hospitals for their clinical training, and through a simple random sampling method, nursing students were selected. The following formula was used to calculate the sample size:

$$
n=\frac{\alpha^{2}\left(Z_{\beta}+Z_{\alpha}\right)^{2}}{d^{2}}
$$

The target population was 282 with the accessible population of 182. Based on sample size calculation, the required sample is 110 and the expected drop-out rate is $10 \%$, so the sample number multiplied by $1(1-0.1)$ and increased number of subjects $(110 \times 0.1)=11$. The calculated final sample was $121(110+11)$ rounded to 125 in which one dropped out after selection, so only 124 participants were selected. The students who have more than $80 \%$ of clinical attendance and cleared all the university papers were included in the study.

Data collection instruments used were baseline information and CCQ.

\section{Tool 1: Baseline Characteristics}

Baseline characteristics were used to check the characteristics and attributes of the study participants. In this study, it includes seven items such as age in years, gender, type of university, experience gained from the type of hospital, aggregate marks in a previous academic year (percentage), participation in special clinical programs, and availability of clinical supervisor during the internship program.

\section{Tool 2: Selection of the Clinical Competence Questionnaire}

For assessing the clinical competence, the researcher found a study, where a standard clinical competence tool was 
developed and used. Chang et al in Taiwan developed and validated a CCQ which is a self-assessment instrument for upcoming baccalaureate nursing graduates developed in 2013. The result from the study indicates the CCQ demonstrates good reliability and validity for measuring the perceived clinical competence in nursing students. The Cronbach's $\alpha$ for the entire CCQ was 0.98 . The self-reported CCQ consists of nursing professional behaviors with 16 competencies, skill competence; general performance with 12 competencies with skill competence; core nursing skill with 12 competencies and skill competence; and advanced nursing skills with six competencies. The scores assigned indicate the level of clinical competence of the students. Permission has been obtained from the author to use the same tool for this study. CCQ and baseline characteristics were submitted for validation. Eight experts validated the tool. The level of clinical competency of the participants was assessed based on a rating scale of a maximum score of 5 . Competence is rated as follows:

$1=$ Does not have a clue.

$2=$ Know in theory, but not confident at all in practice.

$3=$ Know in theory, can perform some parts in practice, independently, and need supervision to be readily available.

4 = Know in theory, competent in practice, and need contactable sources of supervision.

5 = Know in theory, competent in practice without any supervision.

\section{Interpretation of Score}

Level of competence interpreted as novice with scores between 1 and 46, advanced learner between 47 and 92, competent learner between 93 and 138, skilled learner between 139 and 184, and expert between 185 and 230.

Pretesting of the tool was done to check the clarity of items, the ambiguity of the language, and the feasibility of the tool. Prior permission was obtained from the authorities of the institution. The pilot study was conducted at the Nitte Usha Institute of Nursing Sciences among the fourth-year BSc nursing students after obtaining permission from the principal. As per the inclusion criteria, 26 BSc nursing students were selected by using a simple random sampling method. Baseline characteristics and clinical competence were collected by using CCQ. Participants had few difficulties in understanding Question no. 46, performing chest tube care with underwater seal management, and this question was modified as performing chest tube care and water seal drainage management in the main study. The results revealed that the remaining questions found to be suitable for the fourthyear BSc nursing students. The students did not face any level of difficulty in understanding the rest of the questions. The main study was conducted in Mangaluru on comparison of clinical competency, before and after the internship program among the 124 final-year nursing students for 8 months duration. The participants were graduating students drawn from three nursing colleges in Mangaluru. Based on the selection criteria, students were contacted and selected from three nursing colleges: 41 students from two colleges and 42 from one college. The selected students after obtaining permissions from principals gathered in a class room of respective colleges. After an adequate explanation about the study's purpose, by assuring confidentiality, informed written consent was obtained from participants. Pretest data were collected by self-report before the internship program and posttest done after the internship program of nursing students. After the initial requirement, students have filled the CCQ it took around 40 to 50 minutes for them to complete the tool.

\section{Protection of Human Subjects' Rights}

The study proposal was submitted and presented in front of the ethical committee for ethical clearance and obtained permission. Permission to conduct the study was obtained from nursing college principals. Informed written consent was obtained from the participants for the study.

\section{Results}

\section{Baseline Characteristics of Students}

All the participants were in the age group of 20 to 23 years. About $98 \%$ of students were female, and $2 \%$ were males. All students were trained in private parent hospitals only. Among 124 participants majority, 57\% were studying under the deemed university. The majority of the participants, $75 \%$, had previous academic year marks between 60 and 75\%. All 124 participants participated in special clinical programs. In total, 49\% participated in basic life support (BLS), 27\% participated in advanced cardiac life support (ACLS), 19\% participated in critical care nursing, and $4 \%$ participated in renal care nursing. The majority of students expressed that clinical supervisors were available during the internship program when the need arises, and $11 \%$ of students expressed the absence of the supervisor in the clinical area.

\section{Pretest and Posttest Difference in the Level of Clinical Competence}

There were no students with a clinical competence of novice before and after the internship program. The majority of the students $(73 \%)$ were advanced learners in the pretest and gained competence as experts (94\%) in the posttest. One skilled learner found in the pretest was promoted to the level of competent learner in the posttest ( - Table $\mathbf{1}$ ).

\section{Effect of Internship Program on the Level of Clinical Competence}

The effect of the internship program on the level of clinical competence shows the following results.

Pretest analysis shows that in the competence of nursing professional behaviors, students have less clinical competency-"do not have a clue at all" in "demonstrating cultural competence" and "adhering to ethical and legal standards of practice" 59 (47.6\%) each. Most of them know in theory, but not confident at all in practice. These results reveal that participants have less competency in the items of nursing professional behaviors before the internship program. Among 
Table 1 Pretest and posttest difference in the level of clinical competence of students

\begin{tabular}{|l|l|l|l|l|}
\hline \multirow{2}{*}{ Level of clinical competence } & \multicolumn{2}{|c|}{$n=124$} \\
\cline { 2 - 5 } & \multicolumn{2}{|c|}{ Pretest } & \multicolumn{3}{c|}{ Posttest } \\
\cline { 2 - 5 } & Frequency & $\%$ & Frequency & \% \\
\hline Novice (1-46) & 0 & 0 & 0 & 0 \\
\hline Advanced learner (47-92) & 90 & 73 & 1 & 0 \\
\hline Competent learner (93-138) & 33 & 27 & 7 & 6 \\
\hline Skilled learner (139-184) & 1 & 0.01 & 116 & 94 \\
\hline Expert (185-230) & 0 & 0 & \\
\hline
\end{tabular}

124 participants, almost every component of nursing professional behaviors needs contactable sources of supervision or not competent in practice without any supervision. Posttest analysis shows that the participants have more clinical competence (know in theory, competent in practice without any supervision) in "understanding patient rights," 80 (64.5\%) and "following health and safety precautions," 72 (58.1\%). The mean value for the pretest was $30.05 \pm 7.23$ and 71.87 \pm 6.93 for the posttest. The $p$-value is $<0.001$, which is significant.

Pretest analysis of general performance (12 items) shows that participants have less clinical competency-"do not have a clue at all" in "assessing elimination," 58 (46.8\%) and "educating patients or families with disease-related care knowledge," 50 (40.3\%). Most of them know in theory but not competent in practice. Posttest shows that participants have more clinical competence (know in theory, competent in practice without any supervision) in "taking a history for new admissions" and "performing and documenting patient health assessment," 81 (65.3\%) each. Eighty (64.5\%) subjects are competent in developing care plans for patients. The mean value for the pretest was $22.49 \pm 5.27$ and $54.51 \pm 4.21$ for the posttest. The $p$-value is $<0.001$, which is significant.

In the pretest, core nursing skills subjects have less clinical competency in "administering intravenous (IV) medications," 42 (33.9\%), and "performing urinary catheterization and care" and "performing upper airway suction," 40 (32.3\%) each, that is, they do not have a clue at all about the core nursing skills. The posttest shows that participants are more competent in the item "changing IV fluid bottle or bag 85 (68.5\%) and administering IV medication 83 (66.9\%). They are competent enough to do without any supervision. The mean value for the pretest was $23.54 \pm 5.28$ and $54.46 \pm 4.06$ for the posttest. The $p$-value is $<0.001$, which is significant.
Pretest advanced nursing skill show participants have less clinical competency in the item "performing chest tube care and water seal drainage management," 60 (48.4\%), and "performing postural drainage, percussion, and oxygen therapy," 50 (40.3\%), that is, they do not have a clue at all about the advanced nursing skills. The posttest shows participants are more competent in "performing venipuncture," 64 (51.6\%) and starting IV injections, $62(50 \%)$. The mean value for the pretest was $10.69 \pm 2.78$ and $26.51 \pm 2.34$ for the posttest. The $p$-value is $<0.001$, which is significant (-Table 2 ).

The paired $t$-test was used to compare the difference in the level of clinical competence before and after the internship program. It indicates the internship program is effective. The effect of the internship program shows clearly that calculated values are more than the table value, and also, the $p$-values are $<0.001$. Hence, there is a difference in the level of clinical competence before and after the internship program. Hence, the research hypothesis (H1) for clinical competence is accepted.

Chi-square test was used to find the association between the baseline characteristics with the level of clinical competence since there is an association between the clinical competence with selected baseline characteristics (gender and special clinical program), the research hypothesis (H2) for the clinical competence accepted at $5 \%$ level of significance.

\section{Discussion of the Study Findings}

In the present study, the result showed that the subjects who participated in the special clinical program have higher clinical competence compared with others ( - Fig. 1 ). Findings show that $27 \%$ of them participated in the ACLS program, $49 \%$ in the BLS program, $19 \%$ in critical care nursing, and $4 \%$ in renal nursing. A similar finding observed in a study

Table 2 Effect of internship program on the level of clinical competence

\begin{tabular}{|c|c|c|c|c|c|c|}
\hline \multirow[t]{2}{*}{ Competence } & \multicolumn{2}{|c|}{ Pretest } & \multicolumn{2}{|c|}{ Posttest } & \multirow{2}{*}{$\begin{array}{l}\text { Mean } \\
\text { Difference }\end{array}$} & \multirow[t]{2}{*}{ p-Value } \\
\hline & Mean & SD & Mean & SD & & \\
\hline Nursing professional behaviors & 30.05 & 7.23 & 71.87 & 6.93 & 41.82 & $<0.001$ \\
\hline General performance & 22.49 & 5.27 & 54.51 & 4.21 & 32.02 & $<0.001$ \\
\hline Core nursing skills & 23.54 & 5.28 & 54.46 & 4.06 & 30.92 & $<0.001$ \\
\hline Advanced nursing skills & 10.69 & 2.78 & 26.51 & 2.34 & 15.82 & $<0.001$ \\
\hline
\end{tabular}

Abbreviation: SD, standard deviation. 


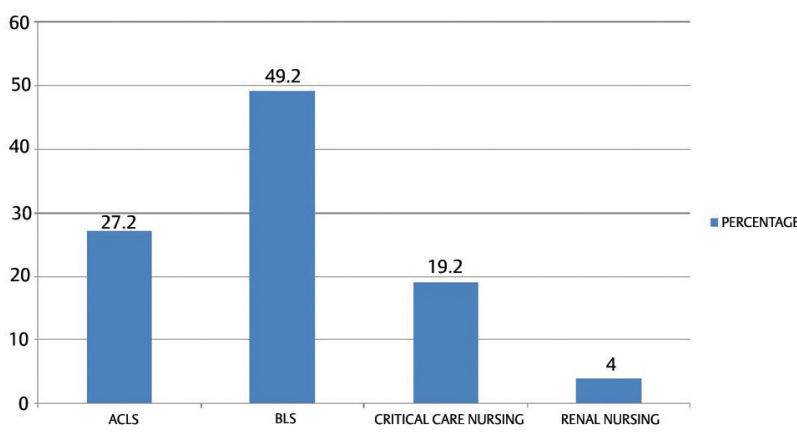

Fig. 1 Bar diagram depicting distribution of participants according to the participation in the special clinical program.

conducted in Taiwan shows that the students who participated in the academic cooperation program had a significant improvement in nursing clinical competence than who participated in an externship program. ${ }^{6}$

The availability of clinical supervisors made a lot of differences in clinical competence in students ( - Fig. 2). A cross-sectional explorative research study findings revealed parallel results in Malawi that students gained more confidence and competence in clinical practice when supported by preceptors as well as achieved clinical learning outcomes. ${ }^{7}$

In the present study, results show that before the internship program, the level of clinical competences (nursing professional behaviors, general performance, core nursing skills, and advanced nursing skills) was less, and they were found to be more competent in each of the competent skill after the internship program.

The paired $t$-test was used to compare the difference in the level of clinical competence before and after the internship program. The obtained $p$-values are less than 0.001 , so there is a difference in the clinical competence level after the internship program.

Another similar quasi-experimental study conducted by Blanzola et al was "nurse internship pathway to clinical comfort, confidence, and competency" at the U.S. Navy Hospital. The purpose of the study was to report the outcomes of a nurse internship program. The result shows that the

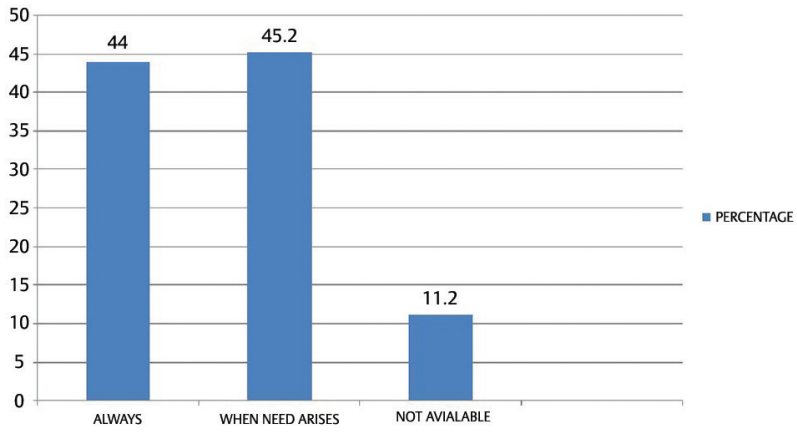

Fig. 2 Availability of the clinical supervisor during internship program. experimental group scored significantly higher on organizational cocompetencies than the control group. ${ }^{8}$

This study finding was also facilitated by a study conducted in North Carolina on "a retention strategy for newly graduated nurses: an integrative review of orientation programs." The hospital provided an orientation program for newly graduated nurses to facilitate the transition from novice to advanced beginner. The result showed that it increased the confidence and competency level of new nurses. ${ }^{9}$

The present study revealed that there is an association between the special clinical program and the level of clinical competency since the $p$-value in the chi-square test was less than 0.001 . In this study, the students participated in special clinical program were 61 (49.2\%) in the BLS, $34(27.2 \%)$ in ACLS, 24 (19.2\%) participated in critical care nursing, and $5(4 \%)$ in renal care nursing. Students who participated in the special clinical program have higher clinical competence than those who have not participated. These study results supported by a study on the evidence of clinical competence by simulation revealed that clinical competence could be made evident and developed by simulation. ${ }^{10}$

Another similar finding in a study on baccalaureate nursing students' preceptorship program and the development of clinical competence revealed that students who participated in preceptorship program gained more level of clinical competence than the students who worked as nursing assistants in a noninstructional clinical setting. ${ }^{11}$

\section{Limitations}

- The study was limited to 124 BSc nursing students who are trained only in private hospitals.

- The data were collected only from three colleges.

- Self-reporting competencies have a chance of overestimation.

- The study assessed only four domains of clinical competence.

\section{Conclusion}

In the present health care system, the services of competent nurses are an inevitable requirement. Though many nursing colleges bring out many nurses, they fail in making skillful nurses. Here comes the importance of skill training or in other words, the internship program. Exposure to the clinical field and practice through an internship program can help nurse students to improve skills. From this study, the researcher found that the internship program has a great impact on improving clinical competence among nursing students.

\section{Funding}

This research was supported by Nitte (Deemed to be University) grantee (Grant number NUINS/CON/NU/ IEC/2015-16, February 18, 2016). 


\section{Conflict of Interest}

None declared.

\section{Acknowledgments}

The authors are indebted to 4th year BSc Nursing students for their assistance with the collection of data and valuable support throughout the study.

\section{References}

1 Papadopoulos I. The Papadopoulos, Tilki and Taylor model of developing cultural competence. In Papadopoulos I, ed. Transcultural Health and Social Care: Development of Culturally Competent Practitioners Edinburgh: Churchill Livingstone Elsevier; 2006:7-24

2 Simpson E, Courtney M. Critical thinking in nursing education: literature review. Int J Nurs Pract 2002;8(2):89-98

3 Institute of Medicine (US), Committee on the Robert Wood Johnson Foundation Initiative on the Future of Nursing. The future of Nursing: Leading Change, Advancing Health. Washington, DC: National Academies Press; 2011

4 Liou SR, Cheng CY. Developing and validating the clinical competence questionnaire: a self-assessment instrument for upcoming baccalaureate nursing graduates. J Nurs Educ Pract 2014;4(2):56-66

5 Cheng CY, Liou SR, Hsu TH, Pan MY, Liu HC, Chang CH. Preparing nursing students to be competent for future professional practice: applying the team-based learning-teaching strategy. J Prof Nurs 2014;30(4):347-356

6 Cheng CY, Tsai HM, Chang CH, Liou SR. New graduate nurses' clinical competence, clinical stress, and intention to leave: a longitudinal study in Taiwan. ScientificWorldJournal 2014;2014:1-9

7 Johnston C, Mohide EA. Addressing diversity in clinical nursing education: support for preceptors. Nurse Educ Pract 2009;9(5):340-347

8 Blanzola C, Lindeman R, King ML. Nurse internship pathway to clinical comfort, confidence, and competency. J Nurses Staff Dev 2004;20(1):27-37

9 Park M, Jones CB. A retention strategy for newly graduated nurses: an integrative review of orientation programs. J Nurses Staff Dev 2010;26(4):142-149

10 Lejonqvist GB, Eriksson K, Meretoja R. Evidence of clinical competence by simulation, a hermeneutical observational study. Nurse Educ Today 2016;38:88-92

11 Scheetz LJ. Baccalaureate nursing student preceptorship programs and the development of clinical competence. J Nurs Educ 1989;28(1):29-35 